\title{
A Lost Fight Book: Alfred Lister and the Noble Art of Self-Defence in China
}

\author{
Benjamin N. Judkins, \\ Cornell University East Asia Program, Visiting Scholar \\ Co-editor, Martial Arts Studies \\ ben.judkins@gmail.com
}

\begin{abstract}
In 1874 an anonymous author published a partial English language translation and discussion of a now lost Southern Chinese martial arts manual originally titled Selected Techniques of Hero Boxing. This was a critical period in the development of the modern Chinese martial arts. Many of the best known Southern Chinese fighting systems (Hung Gar, Choy Li Fut, Wing Chun, White Crane, etc.) were just starting to assume a recognisable form. Yet it is also a poorly understood era. Just as importantly, it was during the mid- and late nineteenth century that Western soldiers, administrators and adventurers first began to encounter and describe the Chinese martial arts. For better or worse, their records would help shape the perception of China in the popular imagination. This chapter begins by identifying Alfred Lister, a civil servant in Hong Kong, as the previously unknown author of this English language work. It then attempts to reconstruct the structure and contents of the fight book which he encountered. Lastly, it investigates the consequences of the misreading of this text.
\end{abstract}

Keywords - Chinese Martial Arts, Kung Fu, Guagdong, Southern China, Hong Kong, Guangzhou, Pearl River Delta, Hero Boxing, Alfred Lister, Translation

\section{INTRODUCTION: A MAN AND A BOOK}

Brian Kennedy and Elizabeth Guo have observed there is no subject more beloved in the world of kung fu fiction than the lost training manual. ${ }^{1}$ Countless films, TV programmes, and wuxia novels have focused on the image of a lost (or better yet, stolen) book that holds the secrets to ancient fighting prowess. Heroes and heroines go to amazing lengths to procure such a book and unravel its secrets. Both a source of arcane knowledge, and an outward sign of martial excellence, in the fictional world of the "Rivers and Lakes" such fight books became the ultimate markers of one's social status.

This article explores a more concrete example of a "lost" fight book, yet it is of no less value as it offers a unique set of insights into the evolving nature of the Southern Chinese martial arts in the Pearl River Delta region of Guangdong province during the late Qing dynasty. It was first discussed in English under the title "The Noble Art of Self-Defence

${ }^{1}$ Kennedy and Guo, Martial Arts Training Manuals, p. xiii. 
In China”, by an author going by the initials L. C. P., in a 1874 issue of The China Review. ${ }^{2}$ The timing of this piece makes it of particular interest as, folkloric claims of improbably ancient genealogies notwithstanding, this was the era when many of the region's iconic martial arts styles (Hung Gar, Choy Li Fut, Southern Mantis, Wing Chun, White Crane, etc.) were coming into being. Sadly, the development of the Southern Chinese martial arts during the late Qing remains poorly understood. Any easily datable publication that opens a window onto this specific time and place is much appreciated.

That fact notwithstanding, the few historians who have concerned themselves with the Chinese martial arts have failed to notice this brief work. It has never been described in modern martial arts studies literature. There are likely a variety of reasons for this. The original Chinese language manuscript which L. C. P. translated for The China Review was thought to have been lost; this made it impossible to access his primary sources. The somewhat eccentric and anonymous nature of the translation also made it difficult to assess in a scholarly sense. Finally, many modern readers will find the tone of his discussion of the region's fighting practices to be extraordinarily ethnocentric and perhaps even racist. Given the current popularity of the Asian martial arts, and the high degree of social acceptance that all sorts of traditional fighting practices now enjoy, encountering period accounts produced by nineteenth-century Western imperialists can be a jarring experience.

Nevertheless, appearances can be deceiving. The author of the article, itself a combined translation and commentary on a popular fight book, was probably less hostile towards Chinese culture than one might at first assume. Given his importance as an early observer of these practices, and his role in shaping early perceptions of Chinese martial arts, this article will seek to identify the previously unknown author and to contextualise his translation. It also offers a brief description (so far as it can be reconstructed) of the original Chinese language document that L. C. P. encountered.

While the actual text of this work remains lost, in recent years at least two related (though slightly different) editions of this same work have come to light. The first is in the rare manuscripts collection of the Bibliothèque nationale de France. ${ }^{3}$ All of the pages and images described in the China Review are included in the third section of this undated nineteenth-century volume. However, its first and second parts are not attested in the Review's discussion. Interestingly, it also lists an author, Gao Xingfang (高興方), while L.C.P.'s edition was anonymous. In its totality the $\mathrm{BnF}$ edition is twice as long as the text that L.C.P. encountered, and it includes a complete written description of an introductory, unarmed, taolu in simple prose. The author of this article has also located, and has in his possession, a hand-copied manuscript of yet another version of this manual. It appears to have derived from a previous print edition as it directly copies a printed title page similar to that seen in the $\mathrm{BnF}$ version. However, it contains a

\footnotetext{
2 Lister, 'The Noble Art of Self-Defence in China'.

3 Paris, Bibliothèque nationale de France, MS Chinois 5640.
} 
different number of pages, which occur in a different order, than either L.C.P.'s book or the BnF copy. Lastly, William Wightman Wood, in the pages of the Canton Register, describes coming across another printed edition of this same (or a very closely related) work in 1829. The text that he describes is not as complete as the BnF's edition but does have additional material that L.C.P. does not describe. As such, scholars currently have evidence of four different version of the same basic Hero Boxing manual. Two of these are extant, while the other two are now lost but are attested in nineteenth-century discussions and partial translations. Taken together they suggest a complex fight book tradition which circulated in various printed editions, and even hand-copied manuscripts, in the nineteenth-century marketplaces of the Pearl River Delta region of Southern China. A complete comparative discussion (and reconstruction) of these works is beyond the scope of the current discussion and will be published separately. This chapter focuses instead on the ways in which one of these short books helped to shape Western understandings of Chinese hand combat after it was partially translated and discussed in the pages of The China Review.

This article concludes that the "The Noble Art of Self-Defence in China" was almost certainly written by Alfred Lister (d. 1890). If he is remembered at all, it is as a middling official in Hong Kong's late nineteenth-century civil service who eventually reached the rank of acting Treasurer and Postmaster General. What is not generally appreciated is that Lister, in addition to being a fine linguist, had a passion for Cantonese popular culture and "street literature". Indeed, he seemed to be drawn to the martial arts as he felt that they were important to anyone who wished to understand China's non-elite popular culture. The subsequent development of the field of martial arts studies suggests that, in this respect at least, he was totally correct. A careful observer of public life, it was his almost Dickensian interest in gambling dens, opera theatres, and public marketplaces that brought him into contact with various aspects of Chinese martial arts. It should be clearly stated, however, that Lister's interests were neither historical nor hoplological. He was not hoping to master these fighting systems; his fascination was more anthropological in nature. By understanding these practices, Lister hoped to grasp a unique aspect of Cantonese culture, and also to comment on universal patterns that he perceived in marginal individuals around the globe who engaged in similar combative behaviors as a way of producing social status. Due to Lister's sardonic style and harsh judgments about the effectiveness of "Chinese boxing," most individuals who have come across his works have seen them as little more than a curiosity, dismissing them as typical products of nineteenth-century imperialist attitudes. A deeper reading of Lister's work reveals someone with a much more complex relationship with his environment.

\section{WHO WAS ALFRED LISTER?}

Lister's story begins not with his birth, but the British acquisition of Kowloon in 1860. Faced with the need to communicate with a vastly expanded Chinese community, the colony's administration put in place plans to upgrade their civil service and institute training programs for talented young translators. These would be selected from the ranks 
of the United Kingdom's middle-class schools. The promise of a healthy salary and rapid advancement attracted several applicants and Lister was a member of the second training class accepted into government service in 1865. ${ }^{4}$

Unfortunately, the early years of Lister's career were inauspicious. Rather than completing the preparatory program which his contract promised, ongoing staff shortages demanded that he be rushed into several offices that put Lister on the front lines of the colony's interaction with its Chinese residents. These assignments were both administrative (harbour master, post master) and judicial (justice of the peace, coroner, sheriff) in nature. ${ }^{5}$

Early in his career we find records of Lister being involved with the first attempts to regulate Hong Kong's brothels in an effort to stop outbreaks of infectious disease. He later caused a scandal reaching all the way to parliament when he wrote a report documenting the deplorable conditions in a Chinese charity temple that was used to store bodies and coffins waiting to be shipped home for burial. As Lister noted, not all of the residents of the facility were actually dead at the time they were dumped there, and his report on the conditions in what was actually a hospice led, more or less directly, to the creation of the first modern hospital for Chinese residents in Hong Kong. ${ }^{6}$

Lister's writings (particularly his anonymous ones) suggest an individual who was quick to criticise his fellow administrators and, more generally, the follies of the Western community in China. While to modern ears his judgments are harsh, period readers likely perceived someone with too much interest in Chinese culture given his administrative responsibilities to the crown. As such, it is probably no surprise that Lister's career plateaued early and, as his obituary in the North China Herald noted, he died in 1890 with few friends. Still, that same obituary went on to remember Lister's many publications as a younger man fondly. ${ }^{7}$ While his professional life was consumed with administrative duties, his contemporaries remembered him mostly as a writer.

Lister was particularly interested in poetry. In that realm he was a talented literary critic and also an amateur poet. ${ }^{8}$ This part of his writing would not, at first, appear to have anything to do with fight books. Still, it is important to review this material as in his engagements with such noted figures as the sinologists James Legge, Lister clearly lays out his own understanding of the nature of translation and its role in the creation of cross-

\footnotetext{
4 Tsang, Governing Hong Kong, pp. 19-22.

5 Ibid.

${ }^{6}$ Howell, 'Race, space and the regulation of prostitution in Colonial Hong Kong', pp. 229-48; Tsang, A Modern History of Hong Kong, p. 68; Fletcher, 'Hybridity in Hong Kong: the Tung Wah Hospital'.

7 The North-China Herald, p. 570.

8 Ibid.
} 
cultural understanding. ${ }^{9}$ All of this would affect the ways that he translated, and transformed, the image of the Chinese martial arts.

Lister's first treatments of the martial arts also arose out of a chance convergence of his literary and administrative pursuits. In 1869 the Duke of Edinburgh undertook a highly publicised tour of Hong Kong. The royal visit generated much excitement and Lister was swept up in the occasion. Notably, he was present at the Tung Hing Theatre where the Duke watched two Cantonese operas, probably in his capacity as a translator. The first of these was a historical drama. The second was more interesting. It was an earthy farce, titled A-lan's Pig, whose plot revolved around compulsive gambling, domestic abuse, and the martial arts.

Lister initially wrote a short summery of this kung fu comedy for a memorial book celebrating the Duke's visit. ${ }^{10}$ Yet it appears that something about the opera, and both the linguistic and cultural challenges of translating it, caught his attention. In the first issue of The China Review (1873) readers were graced with an article, signed by Lister using his own name, in which he provided both a translation of the play and enough background discussion of the martial arts to make it sensible to a Western audience. ${ }^{11}$

He relates to his readers that while searching for street literature in the city's various marketplaces (one of his favourite pastimes) he came across a libretto for the opera in the stall of a local book seller and immediately set about translating it. Yet the libretto for a Cantonese opera is very sparse compared to a Western script. What Lister found resembled an outline of plot points. It was not something that offered a comprehensive description of how the show was to be staged. To give his readers a better sense of what was actually experienced by the audience, Lister took it upon himself to add a list of characters, descriptions of costumes, stage directions, dialogue and even specific jokes (typically these would have been adlibbed on a nightly basis and thus always changing). He was clearly more interested in interpreting the entire sensory experience of a Cantonese opera than in offering a strict translation of the text at hand.

Nor was this simply a matter of enthusiasm. In Lister's (fully developed and explicitly articulated) view, the rights of an audience to grasp the feeling and experience of a text vastly outweighed whatever rights an author might claim to a faithful translation. And to make something meaningful to a Western audience it needed to employ, or be related to, cultural signs that they were already familiar with. In short, Lister argued that any translation of a text must be in part a transformation. Rather than being resisted or minimised, this infidelity to the original should be embraced for the sake of conveying cross-cultural knowledge to the reader.

\footnotetext{
${ }^{9}$ Lister, 'Dr. Legge's Metrical Shi-King', pp. 1-8.

10 Thomson and Beach, Visit of His Royal Highness the Duke of Edinburgh, pp. 28-32.

${ }^{11}$ Lister, 'A Chinese Farce', pp. 25-31.
} 
Anticipating criticism for the fact that he was placing English folksongs, rather than Chinese ones, in the mouths of his Cantonese actors he noted:

So, as "Ah" or "Oh" is not a common termination to English melodies of the less instructed classes, and as those classes certainly do incline to fol-lol (or words to that effect) as a refrain, I my stand on fol-lol, I stake my reputation on fol-lol! ${ }^{12}$

This grandiose declaration was made for comedic effect; Lister was, after all, translating a farce. But it also gives us some idea of the issues that we must consider when encountering his discussions of martial arts.

\section{LISTER AND CHINESE BOXING}

While we typically imagine the martial arts as a strictly embodied phenomenon, Lister was fascinated by the words that were used to describe them. He immediately hypothesised that Chinese martial artists, much like their counterparts in the London ring, had developed their own technical vocabulary for labelling their actions. That was a critical aspect of any attempt to create a sub-cultural identity. Lister supposed that on a sociological level, mastering this sort of vernacular code was a mechanism by which members of the economic underclasses sought to gain a measure of social respect or status among their peers. ${ }^{13}$

Whether any sort of boxing actually functioned as a civilising mechanism, or if fighters (in either the East or West) could claim a degree of social respect was something that Lister seriously doubted. He was intellectually interested in popular culture but, ever the critic, he did not romanticise it. It seems that most of the martial artists that Lister was aware of were either patent-medicine salesmen, soldiers, retired opera singers, or gamblers. Members of all of these groups commonly practiced the martial arts, but they also occupied very marginal positions within China's social hierarchy. ${ }^{14}$ They were also the sorts of individuals who one was likely to encounter while serving in a judicial capacity.

Of all of these groups the gamblers seem to have deserved special consideration in Lister's estimation, possibly as the martial artists in the opera that he published were also gamblers. An anonymous article titled "Chinese Boxing" in the North China Herald in

\footnotetext{
12 Lister, 'A Chinese Farce', p. 26.

13 "It is a fact that, for less than a penny, you buy at a stall in a Chinese street a brochure called, in so many words, The Noble art of self-defence, and that the purchaser who is about to read it will be curiously reminded of whatever he may have heard of the slang of the ring at home, by phrases, not so literally exact as the above, but quite sufficiently suggestive of 'stand firm on your pins,' 'pop in your left,' 'hit strait from the shoulder,' and 'let him have it in the bread-basket"'. Lister, 'The Noble Art of Self-Defence in China', p. 85. Allusions to the language of fighting such as this pepper Lister's writings.

14 Bortez, Gods, Ghosts and Gangsters; Judkins and Nielson, The Creation of Wing Chun, pp. 100-103.
} 
1872, almost certainly written by Lister, hits on several of his favourite points. ${ }^{15}$ It gave an account of a recent fight in Shanghai in which one gambler accidentally killed another in the middle of an impromptu challenge match. The affair was a tragedy that destroyed multiple lives. While the entire account is worth studying in detail (again, there are very few contemporaneous foreign language discussions of the Chinese martial arts of any sort from the 1870s), the following passages are most critical to the current discussion:

If there is one particular rather than another in which we might least expect to find John Chinaman resemble John Bull, it is in the practice of boxing. The meek celestial does get roused occasionally, but he usually declines a hand to hand encounter, unless impelled by the courage of despair. He is generally credited with a keen appreciation of the advantages of running away, as compared with the treat of standing up to be knocked down, and is slow to claim the high privilege the ancients thought worthy to be allowed only to freemen, of being beaten to the consistency of a jelly.

How the race must rise in the estimation of foreigners, therefore, when we mention that the noble art of self-defence and legitimate aggressiveness flourished in China centuries probably before the "Fancy" ever formed a ring in that Britain which has come to be regarded as the home of boxing. Of course, like everything else in China, the science has rather deteriorated than improved; its practice is rough; its laws unsystematized; its Professors are not patronized by royalty nor petted by a sporting public; the institution is a vagabond one, but an institution none the less.

...Boxing clubs are kept up in country villages, where pugilists meet and contest the honours of the ring. Unfortunately, popular literature does not take cognizance of the little "mills" in which the Chinese boxer "may come up smiling after round the twenty-fifth," nor are the referees, if there be any, correspondents of sporting papers, so that we are unable to tell whether the language is rich in such synonyms as "nob," and "conk," and "peepers," and "potato-trap." But if boxers appreciate, as much as their foreign brethren, the advantages over an ignorant and admiring mob which the assumption of a peculiar knowledge gives, we may well suppose that, as they smoke their pipe and sip their tea, they talk over the prowess of the Soochow Slasher or the Chefoo Chicken in a terse and mystic phraseology, embellished with rude adjectives and eked out by expressive winks.

This article was important as it gave Lister an initial chance to both explore the social milieu of the Chinese martial arts as well as to anticipate the linguistic resonances between

15 'Chinese Boxing', pp. 25-26. 
Chinese and Western modes of boxing. Just as importantly, it provided him with an opportunity to begin to blend the two for the sake of his reader.

Indeed, any English language article on the Chinese martial arts written at this time would face unique challenges. During the late nineteenth century there was no single accepted term for the Chinese martial arts. In English, the phrase "martial arts" would not come into common use until the 1970s, and "kung fu" would not be promoted as catchall for foreign language discussions of these fighting systems by the Jingwu Association until the 1920 s. ${ }^{16}$ In the late nineteenth century English speakers relied on a bewildering pastiche of terms to describe what they saw. These included (but are not limited to) boxing, gymnastics, juggling, dancing, pugilism, training, fencing, and acrobatics, all of which might be used to describe a standard martial arts exhibition. Mulling this over, Lister decided that what he was seeing was essentially a Chinese analogue for "the noble art of self-defence", which, by the late nineteenth century had come to be used as a nostalgic term for boxing. Indeed, it would become something of a catchphrase that marked Lister's writings on the martial arts.

\section{DISCOVERING THE NOBLE ART OF SELF-DEFENCE}

In the 1872 article cited above, Lister seems to suggest that he may have been searching the popular Chinese literature for information on "boxing" but had found nothing. This led him to suppose that, just as in the United Kingdom, the Chinese martial arts existed as primarily an oral and embodied culture. ${ }^{17}$ Fortunately, his luck changed sometime between 1872 and 1874 when he returned to the pages of The China Review in 1874 with an anonymously published article titled "The Noble Art of Self-Defence in China".

This work (signed L. C. P.) begins with an extended editorial discussion of the uncanny correspondences that one finds between parallel institutions in China and the West. Lister's foray into structuralism provides him with an opportunity to introduce Chinese boxing and his latest document discovery. More specifically, Lister proceeds to give a partial translation and commentary on a very brief fight book which he titles "The Noble Art of Self-Defence".

While claiming that what follows is a "direct translation", he is also kind enough to provide the book's original title in Chinese for anyone to examine it. ${ }^{18}$ A more literal translation of the work would actually be something like "The Tearing Down Techniques

\footnotetext{
16 Molasky, 'The Phone Book Project', pp. 57-72; Judkins, 'Jingwu and the Creation of the 'Kung Fu' Brand'; Judkins, 'Inventing Kung Fu'.

17 "As in England, so in China, the noble art of self-defence seems to be handed down rather by oral tradition than by books". Lister, 'The Noble Art of Self-Defence in China', pp. 85-86.

18 According to the first footnote in Lister's 1874 article, the original title was “雄拳拆法”.
} 
of Hero Boxing". ${ }^{19}$ This makes sense as "self-defence", whether noble or otherwise, was not a descriptor that was used to name Chinese martial arts at the time. "Hero Boxing", however, is an idiomatic construction that makes frequent appearances in several sets associated with various martial arts that emerged in Southern China (and other regions) in the late nineteenth century. This entire passage seems to be a reflection both of Lister's sardonic sense of humour and a wink towards his previously published thoughts on the value of literal translations. Shortly thereafter, attentive readers will find him approvingly citing his own translation of $A$-lan's Pig. ${ }^{20}$

Unfortunately, Lister's manual claimed no author, probably because printing and commercially distributing something like this in late-imperial China was frowned upon by the authorities. They tightly regulated the printing industry as well as the martial arts behaviours that may or may not be tolerated in a given place. ${ }^{21}$ This reflected not only a desire for peace and stability in the marketplace, but also the assumed social marginality of China's martial artists.

It was likely the illicit nature of this publication that first brought it to Lister's attention. John Christopher Hamm, while writing on the early history of Guangdong's martial arts novels, noted that a vibrant black market in popular literature and critical newspapers had sprung up in the region between British controlled Hong Kong and Guangzhou. Questionable material could be printed on the British side of the colonial border, then shipped upstream for sale, effectively bypassing imperial censorship. This porous border became critical to the development of the region's distinctive martial arts literature. ${ }^{22}$

Lister describes this fight book as being a brochure or pamphlet. It was printed with crudely executed wood blocks and was sold commercially for less than a penny in the sorts of stalls dedicated to his beloved "street literature". ${ }^{23}$ The golden age of the Chinese fight book tradition occurred in the final decades of the Ming dynasty when the imperial military commissioned vast encyclopaedias and members of the gentry began to search for ways to better train local militias in the face of increased disorder. These more systematic, better produced, works have already been discussed by a number of military historians and researchers within martial arts studies. ${ }^{24}$ In contrast, the plebian fight book which Lister encountered was basically a type of working-class ephemera. It was not the sort of publication that would attract the interest of manuscript collectors or libraries and

\footnotetext{
19 Personal correspondence with Douglas Wile, who offered invaluable linguistic assistance in deconstructing Lister's "literal" translations.

${ }^{20}$ Lister, 'The Noble Art of Self-Defence in China', p. 85.

21 One of the classic discussions of the finely grained ways in which these regulations could be enforced and tailored to specific circumstances during this period can be found in Esherick, The Origins of the Boxer Uprising.

22 Hamm, Paper Swordsmen, pp. 40-41.

${ }^{23}$ Lister, 'The Noble Art of Self-Defence in China', p. 85.

24 See for instance Shahar, The Shaolin Monastery; Lorge, Chinese Martial Arts.
} 
that probably explains why so few copies of it have survived. Its existence, and importance, would have been totally forgotten had a copy of it not fallen into Lister's possession.

Lister goes on to describe the volume as being comprised of a title and eleven additional pages whose exact dimensions are never given. Each page followed the same format and included images of two individuals stripped to the waist and engaged in combat. ${ }^{25}$ The fighters were shown using different techniques which were labelled and described in simple prose. It seems that this work lacked the more sophisticated rhyming couplets that are often seen in late imperial manuals. Admittedly, the exact nature of the text is something of an educated guess as Lister's copy is no longer extant. Yet given Lister's interest in Chinese poetry (and his status as a self-proclaimed literary critic), if he had come across badly composed couplets, I suspect that he would have been only too eager to describe them for his readers.

While brief, the book followed a clear organisational scheme. The first two pages (or "lessons", as Lister identifies them) focused on unarmed boxing. The next three covered pole fighting. After that there were five discussions of the budiedao (paired short "butterfly swords" held in each hand) or similar arms. This was a very popular weapon in Southern China, often used in militia training and given to security guards. The attention that it received in the manual seems to reflect that social reality. The final two lessons focused on the use of woven wicker shields. It is also worth remembering that poles, spears, budiedao, woven rattan caps, and shields, while seemingly exotic now, were the most common items issued to members of village or gentry militias in Southern China. ${ }^{26}$ It thus seems likely that the original readers of this work may have had some familiarity with each of these subjects.

25 Readers should recall our previous note that while two other extent copies of this work have been located, they both contain a different number (and arrangement) of pages from each other, and from what Lister describes in his 1874 article. As such, we are dealing with a complex manuscript tradition rather than a single work. While these other editions can help to inform our reconstruction on Lister's text, we are still describing a lost fight book. Indeed, Lister's version only contained half as many pages as the copy held by the Bibliothèque Nationale de France (twentyfour pages of instruction with two title pages), or the handwritten manuscript (sixteen pages of instruction with two title pages) in my possession.

26 Wakeman, Strangers at the Gate, p. 95. 


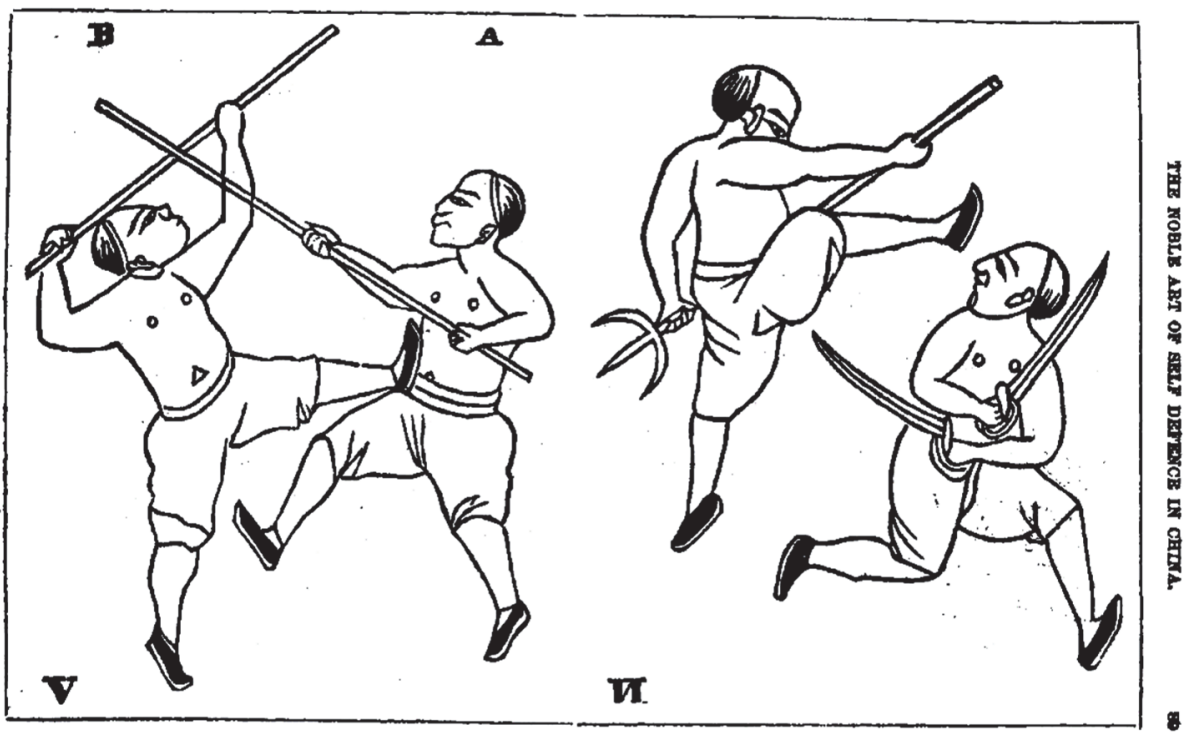

Figure 1: Lister's Reproductions of the Woodcuts for Lessons V Through VIII, pp. 89-90.

Fortunately for modern readers, Lister had a number of the original diagrams reproduced for inclusion in his own commentary on the work. These are stylistically very similar to images seen in other period training manuals. The now widely available Bubishi (a nineteenth-century hand-copied Okinawan/Fujianese manuscript tradition that inspired some of the early pioneers of karate) contains a chapter of very comparable sequences. ${ }^{27}$

Lister was fully aware that most of the information contained in this slim work would be utterly incomprehensible to his Western readers. Even highly experienced modern Chinese martial arts scholars know the frustration of sitting down with Qing era boxing documents. In some cases these are little more than a long list of names meant to prompt the memory of those who were already familiar with the practices in question. ${ }^{28}$ Again, one expects that such a pamphlet would have been of the most interest to students who already had some knowledge of Hero Boxing or a similar art. While the version of this text held at the BnF begins with a very basic two-page written description of a complete

27 The best facsimile reproduction of a rare full color example of this manuscript can be found in Nisan and Liu Kangyi, The General Tian Wubeizhi. More similar to the crudely executed examples seen in Lister's fight book are the ink drawings reproduced in Bubishi: The Classic Manual of Combat. These are generally more representative of the surviving copies that comprise the Bubishi manuscript tradition.

28 For a nice example of the interpretive problem which present themselves is sparse, and sometimes cryptic, Qing era martial manuscripts see Wells, Scholar Boxer, particularly sections such as "71. Monkey Pole" and "72. Double Sword Catalouge", pp. 220-22. 
unarmed form, the more abbreviated printing that Lister encountered simply presumed this sort of familiarity.

Western readers would have had no such head start. As such, Lister does not attempt to present a complete and literal translation of what he found. Instead he reproduced eight of the diagrams from the book, or roughly two-thirds of the original total. Some of these were accompanied by a literal translation of the names of the techniques shown ("Hungry Tiger Catches the Sheep" or "Oyster vs. Snipe"). In other cases, he provided a narrative interpretation of the actions in the diagrams, giving his assessment as to whether or not such a course of action was likely to succeed. In one case he even seems to have borrowed terminology taken from Western military sabre training exercises to better explain to his readers what the two-dimensional Chinese image was really suggesting. ${ }^{29}$ This strongly suggests that Lister was falling back on Western techniques and metaphors in an attempt to convey what he observed within the Chinese martial arts.

Any textual description also needs to take note of some of the features that are not seen in a fight book. Unlike either the Bubishi, or many later Republic era manuals, neither Lister's fight book, nor any of the other texts identified in this manuscript tradition, contained a historical discussion of any kind. While we know that we are looking at "Hero Boxing", no attempt has been made to tell readers who created it, or how it came about. Nor are there the sorts of prefaces that one sometimes sees attesting to the authenticity of the practices outlined within. Lister's book shows no theoretical orientation, nor does it contain any cultural or medical references (subjects commonly encountered in handcopied nineteenth-century boxing manuscripts from Guangdong). This was a pure martial arts manual focusing on the use of commonly encountered weapons.

\footnotetext{
${ }^{29}$ Under the section titled "Number V" we read, "A — stands well up, gets his hands together and strikes a down blow (7th cut) at the same time drawing back his right foot: B-gathers himself well together on his right foot, gets up both ends of his staff ( $7^{\text {th }}$ guard), parries the blow with all of his strength, and at the same time pops in his left foot". p. 91. This is the only place that numbered cuts and guards are mentioned in Lister's text. Even though the section in question discusses pole fighting, one suspect that Lister turned to a reference such as Infantry Sword Exercises - Adjutant General's Office - Horse Guards or even John George Wood's Every Boy's Book: A Complete Encyclopedia of Sports and Amusements. This last work was in circulation while Lister was still in school and its chapter on broadsword fencing (military sabre) seems to be compatible with the interpretations of the underlying Chinese text that Lister offers.
} 


\begin{tabular}{|c|c|c|c|}
\hline Page & $\begin{array}{c}\text { Contents of the Original } \\
\text { Fightbook }\end{array}$ & $\begin{array}{c}\text { Translation or Narration } \\
\text { Given }\end{array}$ & Placement in Lister \\
\hline $\mathbf{1}$ & Title & $\begin{array}{c}\text { "The Nobel Art of Self- } \\
\text { Defence" }\end{array}$ & Page 84 \\
\hline $\mathbf{2}$ & Unarmed Boxing & $\begin{array}{c}\text { "Hungry Tiger Catches the } \\
\text { Sheep" }\end{array}$ & Figure 1 (B) \\
\hline $\mathbf{3}$ & Unarmed Boxing & Narration & Figure 2 \\
\hline $\mathbf{4}$ & Pole v. Pole & Narration & Figure 3 \\
\hline $\mathbf{5}$ & Pole v. Pole & "The Stopper Over All" & Figure 4 (B) \\
\hline $\mathbf{6}$ & Pole v. Pole & Narration & Figure 5 \\
\hline $\mathbf{7}$ & Butterfly Swords v. Trident & Narration & Figure 6 \\
\hline $\mathbf{8}$ & Butterfly Swords v. Glaive & Narration & Figure 7 \\
\hline $\mathbf{9}$ & Butterfly Swords v. Unknown & Omitted & Omitted \\
\hline $\mathbf{1 0}$ & Butterfly Swords v. Unknown & Omitted & Omitted \\
\hline 11 & Double Shields v. Spear & "The Snipe and the Oyster" & Figure 8 (B) \\
\hline $\mathbf{1 2}$ & Shield vs. Unknown & Omitted & Omitted \\
\hline
\end{tabular}

Table 1: A Reconstruction of Selected Techniques of Hero Boxing, Based on Lister's "The Noble Art of Self-Defence in China" (1874).

\section{CATEGORISING THE NOBLE ART OF SELF-DEFENCE}

Given what we now know about Lister's manual on Hero Boxing, how can we situate it in the larger context of Chinese martial arts texts? According to Kennedy and Guo, who have developed a typology of this literature, Chinese fight books can be categorised into five chronological and descriptive categories. ${ }^{30}$ To begin with, there are the ancient or legendary texts which either never existed or have been lost excepts for their titles, recorded in the catalogues of early imperial collections. ${ }^{31}$

Secondly, we have the early woodblock printed manuals of the Ming dynasty (1368-1644), mentioned earlier. The oldest complete Chinese fight books in existence date to the 1500s. Their production and dissemination constitute the start of the "modern" conversation about the Chinese martial arts. ${ }^{32}$

Kennedy and Guo's third category includes hand-written manuscript traditions developed during the Qing dynasty (1644-1912). Government restrictions and declining demand put an end to the golden age of fight book publication that occurred at the end of the Ming. Still, a good deal of material continued to be circulated in written form, often passed directly from teacher to student, during the period of Manchu rule. The previously noted Bubishi manuscript tradition might be the best-known example of this sort of work,

\footnotetext{
${ }^{30}$ Kennedy and Guo, Martial Arts Training Manuals, pp. 96-114.

31 An analysis of these orphaned titles can be quite enlightening. See: Lorge, 'Early Chinese Works on Martial Arts', pp. 13-26.

32 Shahar, The Shaolin Monastery, pp. 55-81.
} 
though as Nisan and Kangyi note, many similar hybrid martial/medical texts circulated in Southern China during this era. ${ }^{33}$ Importantly, Kennedy and Guo conclude that to the best of their knowledge there were no commercial publications of any martial arts books between the seventeenth and the early twentieth centuries.

Lastly, the advent of modern printed martial arts manuals followed the explosion of nationalism that came with the 1911 revolution. These publications made use of new technologies like photography, and often reflect the era's modernist ethos. While some hand written manuscript traditions continued into this era, the mass distribution of printed works describing only a handful of styles helped to unify the public image of the Chinese martial arts.

Lister's discovery complicates this typology. The work that he described is clearly a printed, commercially distributed, manual yet it predates the generally accepted advent of this genre by almost forty years. Was this book a singular exception? One publisher's hobby? Or is it evidence of a once common genre of martial arts themed ephemera that has not survived in modern collections? And if the latter, as is suggested by structural differences in the surviving and described copies, how might it force us to rethink our conclusions about the nature and evolution of the martial arts in the Pearl River Delta during the nineteenth century?

Researching the history of the Chinese martial arts is difficult precisely because of their status as popular, rather than elite, culture. It would not be correct to say that wealthy individuals never took an interest in boxing or military matters. ${ }^{34}$ Yet because these pursuits were not entirely socially respectable, in most cases the Confucian scholars who recorded local and family histories played them down or passed over them in complete silence. As David Robinson noted in his study on the economy of violence in late imperial China, the historical images that these figures created reflected their strong ideological bias and tended to systematically suppress the intrusion of martial and military values into everyday life. ${ }^{35}$

Foreign observers, on the other hand, were often fascinated by displays of "strange" weapons and exotic schools of boxing or wrestling. Period writings by missionaries, merchants, and soldiers in Southern China are an important, if overlooked, source of information on the development of these fighting systems. In some cases, they recorded the sorts of minutia that local observers would simply have ignored as uninteresting or obvious.

33 Nisan and Kangyi, General Tian Wubeizhi, pp. 7-11.

34 Ip Man immediately comes to mind as an individual from a relatively wealthy family who dedicated himself to martial pursuits. Still, he was not the family's eldest son, and thus enjoyed a greater degree of freedom. Even so, such individuals were relatively rare in the late Qing. See Judkins and Nielson, The Creation of Wing Chun.

35 Robinson, Bandits, Eunuchs and the Son of Heaven, p. 9. 
For instance, an entry in the Canton Register (almost certainly written by William Wightman Wood) for 18 June 1829 noted the existence of another printed fight book, very similar to the one that Lister would discover four decades later. Indeed, the appearance of these same pages in the first half of the copy found in Bibliothèque nationale de France suggests that inexpensive printed works on Hero Boxing must have been in circulation for some time. Wood's brief description of the text reads as follows:

Pugilism-The art of self-defense is regularly taught in China. It is much practiced, although not countenanced by the local governments. In the penal code, nothing appears concerning it. Tracts are printed which would, in all probability, accompanied by their wood-cuts, amuse the fancy in England. The Chinese have no pitch battles that we ever heard of; but we have seen a pamphlet on the subject of boxing, cudgeling, and sword-exercise, in which there are many fanciful terms.

The first lesson, for a Chinese boxer, consists of winding his long tail tight around this head, stripping himself to the buff, then placing his right foot foremost, and with all his might giving a heavy thrust with his right fist against a bag suspended for the purpose. He is directed to change hands and feet alternately, restraining his breath and boxing the bag of sand right and left, for hours. This exercise the fancy call "thumping down walls and overturning parapets".

In the second lesson, the pugilist grasps in each hand a "stone lock", i.e., a heavy mass of stone worked into the form of a Chinese lock. Then, being stripped and tail arranged as before, he practices thrusting out at a man's length these weights, right and left, till he is tired. He is to change feet and hands at the same time. This lesson is called "a golden dragon thrusting out his claws". Next comes "a crow stretching his wings—a dragon issuing forth from his den—a drunken Chinaman knocking at your door-a sphinx spreading her wings-a hungry tiger seizing a lamb-a hawk clawing a sparrow-a crane and a muscle reciprocally embraced", with various other specimens or fanciful nomenclature for divers feats of the pugilistic Art. ${ }^{36}$

The basic outline of this work is very close to Lister's manual, yet there are also important differences in the subjects covered. To begin with, this pamphlet (which Wood probably collected in the market near the Western warehouses of Guangzhou), like the example in the $\mathrm{BnF}$, began with exercises that focused on strength training and conditioning. ${ }^{37}$ This

\footnotetext{
36 'Pugilism'.

${ }^{37}$ While similar, it should be noted that the relevant section of the BnF edition of this work contains four lessons not mentioned by Wood including "Hanging a Bell from an Iron Beam," "General Holds up his Seal," "Scholar Receives his Diploma," and "Golden Bell Falls to the Ground".
} 
included both punching heavy hanging bags and a type of weight lifting. Lister's work included no comparable discussion.

Still, the basic format of these commercially printed pamphlets is remarkably similar given that they are separated by over forty years of history (some of which were quite violent). It is also interesting to note that at least two of the combative techniques discussed in Lister's manual are also present in Wood's earlier find ("hungry tiger catches the sheep" and "a crane and a muscle reciprocally embraced"). That speaks, at minimum, to a degree of continuity in regional martial culture.

Lister's article throws Wood's much earlier account into sharp relief and suggests that neither of these nineteenth-century fight books were isolated projects. Rather, the area seems to have had a long running tradition of producing inexpensive martial arts manuals for commercial sale in the sorts of stalls that also sold opera scripts and song books. While it is intriguing to note that both of our accounts suggest that these manuals were being sold in the border region between the Chinese and Western zones of control, it seems highly unlikely that any of the Western warehouses in Guangzhou in the 1820s were hosting black market Chinese publishing companies. Thus, we must conclude that this material was being produced in and for the local marketplace.

I have previously argued, and sought to demonstrate, that the disseminating of the martial arts through commercial schools probably emerged in the Pearl River Delta as early as the mid-nineteenth century and was certainly in full swing by $1900 . .^{38}$ Other authors have claimed that the commercial and public model of martial arts instruction would have been unthinkable prior to the early Republic period and was an innovation created almost solely by the well-known, and nationally successful, Jingwu Athletic Association. ${ }^{39}$

Jingwu did much to redefine the Chinese martial arts as an open and progressive institution in the public imagination. ${ }^{40}$ Still, the early commercialisation and industrialisation of the Pearl River Delta region (due to its importance as a regional and global trade hub) created both a demand for more security and a monetised economy that could support a market in martial services. ${ }^{41}$ The emergence of a print market for primers or ephemera, marketed specifically to the sorts of working-class individuals who were most likely to take up boxing, is further evidence that the commercialisation of the martial arts was well under way by the last quarter of the nineteenth century.

\section{CONCLUSION: BUT IS IT REALLY "CHINESE BOXING"?}

In closing, let us turn our attention to Alfred Lister's role in spreading a certain level of understanding of the Chinese martial arts to nineteenth-century Western readers. The fact

\footnotetext{
${ }^{38}$ Judkins and Nielson, The Creation of Wing Chun.

${ }^{39}$ Kennedy and Guo, Jingwu: The School that Transformed Kung Fu.

40 Morris, Marrow of the Nation, pp. 195-204.

${ }^{41}$ Judkins and Nielson, The Creation of Wing Chun, pp. 89-105.
} 
that he has subsequently been forgotten may lead us to understate his importance at the time. Lister's essay on the "Noble Art of Self-Defence in China" was certainly noticed and it proved so popular that it was reprinted at least twice in various newspapers, including decades after its first release. Each of these reprints amplified the readership of his ideas. And while Lister attempted to obscure his own identity, a later editor of the China Mail (while reprinting and commenting upon a prior reprint from the Straits Times) seems to have enjoyed winking at him as the actual author, identifying him by his office rather than name. ${ }^{42}$

Throughout his various articles and essays, Lister seems to have struggled to understand exactly what Chinese Boxing was. Again, modern conceptual frameworks like the "martial arts", which act as convenient catchalls in our current conversations, did not exist in the 1870s. ${ }^{43}$ He was left to work out for himself what threads connected staged Cantonese opera performances, deadly brawls between professional gamblers, the antics of street performers, and military training exercises. How should we understand the nature of similar practices reoccurring in radically different (if always socially marginal) contexts?

Sadly, this was an area where Lister's theory of translation may have complicated his search for answers. Rather than delving more deeply into the sociology and cultural experience of soldiers, opera singers and criminals, he instead turned to the metaphor of Western boxing with its romantic notion that working-class individuals might both solve their differences and demonstrate their manhood through a constrained but vigorous fistfight, understood as an impromptu sporting exhibition. Lister notes with actual disappointment that Chinese labourers almost never get into fistfights no matter how heated their disagreements. And when things are finally pushed to the breaking point individuals would often come at each other with poles, stones and other improvised weapons rather than engaging in an orderly round of pugilism for an appreciative audience of onlookers. ${ }^{44}$ Lister's cultural expectations about the nature of "normal" social violence

${ }^{42}$ Lister, 'The Noble Art of Self-Defence in China', p. 3. It may also be worth wondering why Lister published this most important piece on the Chinese martial arts anonymously. One certainly sees nameless articles in some period periodicals. Yet it is also hard to overlook the fact that Lister criticised some of his colleagues, and gossiped about prominent visitors, in certain sections of this article. Given that nineteenth-century Hong Kong was a relatively small place for expatriates, he may have decided that discretion was the better part of valour.

43 Molasky, 'The Phone Book Project'.

44 See, for instance, the following observation; "The Chinese have very little idea of fighting with fists. It takes a good deal of vocation to induce them to fight at all. The amount of bad language which will be bandied between two strapping coolies and end in nothing more decisive than bad language would serve to provoke a dozen fights in the British forecastle... When Chinamen do fight, bamboos, or half-bricks are much more in request than nature's unassisted weapons, or if they are driven to an empty-handed encounter they will seize each other by the head and scuffle about in a way which would go to the heart of any member of the sporting interest". Lister, 'The Noble Art of Self-Defence in China', p. 85. This passage, while critical, bears careful consideration. Lister seems to have correctly noted that while violence did occur within the Chinese society, its 
were radically different from those held by his Chinese interlocutors, and throughout his writings they remain unexamined.

It is the spontaneous, vigorous and unscripted nature of Western boxing which frames much of Lister's thinking about the Chinese martial arts. His major criticism of the manual on Hero Boxing is that the techniques outlined within it presuppose a type of prearranged choreography. Rather than attempting to find underlying concepts or principals he reduces every image to a simple exchange of offensive and defensive techniques. And like countless other bewildered neophytes in their first weeks of martial arts training, he cannot help but exclaim, "But what if he had done that instead!"

Lister concludes that ultimately much of this is useless for actual fighting as Chinese Boxing is, at its core, derived from cooperative exercises staged for an audience. ${ }^{45} \mathrm{He}$ does not deny that they require a degree of strength and dexterity, or that in these respects martial artists might actually be a match for the "muscular Christians" of the West. Yet he concludes that their combat systems can be reduced down to sets of simple tricks and, in any case, discussions of polearms and swords seem outrageously outmoded in the era of rifles and gunships. In the article's concluding sentences Lister seemed notably unhappy that these skills still played a prominent role in the selection and training of the Chinese imperial military. ${ }^{46}$

In fairness, the sorts of martial arts exhibitions that Lister encountered in the opera, and even in Hong Kong's marketplaces, actually were staged cooperative exercises. And Lister's supposition that "It is probably actors out of employ who make a precarious living by exhibiting, and professing to teach these tricks in the street," was not entirely wrong. ${ }^{47}$

expression, as well as the cultural norms that regulated it, were quite different from what one might find among the British working class. It is therefore odd that he would go on to expect their methods of martial arts training (or even basic goals) to be similar.

45 "Nay, even what he does describe are only those ad captandum tricks shewn upon the stage, where the pet of the ring, knowing exactly what the other man is going to do, easily discomfits him, bringing his antagonist and the house down together". Lister, 'The Noble Art of Self-Defence in China', p. 86.

46 "The worst of this profitless and dismal foolery is that it is taught to what the Chinese are pleased to call their army instead of anything wholesome or useful... 'Ah,' they say, when they see these useless persons jumping over each other's heads or turning summersaults in the air, 'here are valiant men! You won't easily find an enemy who will get the better of them!' As an excellent proverb of their own has it, where there is no cinnabar they think a deal of red clay!". Lister, "The Noble Art of Self-Defence in China', pp. 91-92.

47 Lister, 'The Noble Art of Self-Defence in China', p. 86. While Lister never indicates any knowledge of the Wing Chun system, it is interesting to note that its creation legend (relayed by Ip Man) specifically claims that two retired opera performers were responsible for teaching it to Leung Jan, who would go on to establish the practice in Foshan. It is also worth noting that Lister's arguments about the theater seem to predate the conclusions advanced by Charles Holcombe by more than a century, though he does not locate the martial arts within the same popular religious 
Such individuals were commonly encountered. Indeed, the Jingwu and Guoshu martial arts reformers of the Republic period would go to great lengths in their attempts to "purify" the Chinese martial arts of precisely these influences. ${ }^{48}$

Yet it is also interesting to consider how similar Lister's criticisms are to those that would remerge a century later when the value of kata or taolu came to be debated within Western martial arts circles by those interested in "reality based" fighting modalities. For that matter, his deconstruction of the images of winning and losing techniques in the Hero Boxing manual are uncannily similar to the criticisms of self-defence sequences published in contemporary martial arts magazines and books. It is remarkable to realise that there is nothing new, modern or iconoclastic about these critiques. They are simply the latest incarnation of a line of criticism that goes back to the West's very first encounters with these practices.

Lister does not attempt to understand how structured drills, or semi-contact interactions, might build certain sort of skills (in both Western and Eastern practices). Nor does he wonder why a body of (largely civilian) martial artists retains such an interest in swords and spears in the 1870s. Indeed, the United Kingdom's control of Hong Kong, the spoils of the Opium Wars, seems to be taken as mute testament that Chinese martial practices have no practical value.

If Western administrators and Chinese reformers in the late nineteenth century could agree on one thing, it was that China's military was badly in need of modernisation and rationalisation. Lister was hardly alone in his criticisms of these institutions. But for him the traditional hand combat systems were a valuable lens for understanding what had gone wrong, they seemed to point to the ultimate sources of China's backwardness. The inability of China's martial artists to even compete in a Western style boxing match at a time when it was suffering one military defeat after another seemed like an apt metaphor, for both Lister and his readers.

In truth, the Chinese martial arts have been asked to fill a dizzying array of social functions over the centuries. They have been many things to many people. But during the late nineteenth century the one role that they almost never took on was that of organised sporting event. ${ }^{49}$ Lister notes with disappointment that only two of the "lessons" in his book are dedicated to actual unarmed boxing. That is $20 \%$ of the total. The other $80 \%$ of the work focuses on defending oneself with spears, butterfly swords, and shields in much more perilous situations.

context which the later researcher (somewhat controversially) emphasizes. See Holcombe, 'Theater of Combat', pp. 411-31.

${ }^{48}$ For more on the ideological aspect of these reforms see Phillips, Possible Origins.

49 Of course, jacketed wrestling bouts were often understood in terms similar to "sporting" matches. Further, the imperial military examinations, which included a tests of archery skills, also seems to have functioned as a public spectacle during the late Qing in Southern China. However, neither of these practices make an appearance in Lister's discussion of "Chinese boxing". 
Lister does not devote much effort to thinking about the social and historical implications of these weapons, but perhaps students of martial arts studies should. The middle years of the nineteenth century were a dangerous time in Southern China, due in no small measure to the growing reach of Western imperialism. The region saw in quick succession the Opium Wars, the Red Turban Revolt and a persistent state of civil war between the Cantonese and Hakka linguistic communities. The Red Turban event alone generated tens of thousands of battlefield casualties..$^{50}$ If that weren't enough, there were also serious piracy outbreaks during the nineteenth century (in which cities and towns were sacked and burned) and very real fears of an impending Western military occupation of the Pearl River. ${ }^{51}$

At multiple points in this period many male residents of Guangdong's Pearl River Delta were forced into militia service, both to protect their home villages and to fight battles on behalf of larger gentry-led military forces. When this happened the three most commonly issued militia weapons were a long pole or spear, a set of butterfly swords, and a rattan shield. A few matchlock arms (and later European pattern rifles) might also be issued to each unit. The more up to date guns and cannons (which became increasingly common after the disturbances of the 1850s) were typically reserved for regular troops. ${ }^{52}$ Thus most militia members went into battle with either a long spear or a set of budiedao. We even have intelligence reports from British naval officers during the Opium Wars reporting (basically in disbelief) that large groups of Chinese recruits were drilling with these traditional weapons.

March the 21st, Lin [the Governor General] was busy drilling 3,000 troops, a third portion of which was to consist of double-sworded men. These twin swords, when in scabbard, appear as one thick clumsy weapon, about two feet in length; the guard for the hand continuing straight, rather beyond the "fort" of the sword turns toward the point, forming a hook about two inches long. When in use, the thumb of each hand is passed under this hook, on which the sword hangs, until a twist of the wrist brings the grip within the grasp of the swordsman. Clashing and beating them together and cutting the air in every direction, accompanying the action with abuse, noisy shouts and hideous grimaces, these dread heroes advance, increasing their gesticulations and distortions of visage as they approach the enemy, when they expect the foe to become alarmed and fly before them. Lin had great faith in the power of these men. ${ }^{53}$

\footnotetext{
${ }^{50}$ For a classic review of violence in the Pearl River Delta during this period see Wakeman, Strangers at the Gate.

51 Antony, Like Froth Floating on the Sea.

52 Wakeman, Strangers at the Gate, pp. 11-21.

53 Bingham, Narrative of the Expedition to China, I, pp. 177-78.
} 
Butterfly swords seem to have originated in Guangdong during the late eighteenth or early nineteenth century. While double weapons are quite popular throughout China, this specific weapon remained a regional specialty in the middle years of the nineteenth century, and its enclosed " $D$ " shaped handguard (very uncommonly seen on Chinese weapons) is likely a result of foreign influences. Anyone familiar with arts like Wing Chun or Hung Gar can attest that these unique weapons are still central to the region's martial identity.

When we find a fight book, sold in the markets of Guangdong, that devotes half of its discussion to the budiedao, or other paired swords, we can be confident that it is reflecting a distinct local martial culture. Lister's pamphlet was not imported from anywhere else, nor was it simply a reprint of badly reproduced pages from an older Ming era military encyclopedia. While there are many questions that we probably just cannot answer about the reconstruction of specific techniques in this text, its intended audience and mixture of topics suggest much about what was motivating the development of local martial arts in Southern China between the 1820s-1870s.

Despite his best efforts, which were in many ways pioneering, Lister never really grasped how the Chinese martial arts functioned within the broader community, or even how its needs and definition of security might be different from his own. He remained trapped by Western cultural paradigms that imagined these systems as either a poor method of athletic sparring (in which little actual pugilism ever happened) or as an outdated method of military training (lacking proper weaponry and drill). Nor was Lister alone among Western observers in this assessment, but by widely publishing his views, he had an undeniably greater impact on the reading public.

It is thus ironic that the Chinese martial arts reformers of the later Republic period (19111949) would so often seek to legitimise their arts by recreating them as either a rationalised sport or a system of more efficient military training. ${ }^{54}$ While Lister may have failed to grasp key elements of his subject, the cross-cultural dialogue that he helped to set in motion would have a profound impact on the development of the Chinese martial arts in the coming century. In the final analysis, it may be difficult to disagree with his early assertion that we cannot translate, we cannot make something legible across cultural boundaries, without at the same time transforming it. Perhaps Lister never anticipated how enduring this conversion would be, or that the marginal fighting styles which he observed would one day become key symbols of the Chinese nation itself.

${ }^{54}$ Morris, Marrow of the Nation, pp. 185-229. 


\section{BIBLIOGRAPHY}

\section{VII.1. Primary sources}

\section{VII.1.1. Attributed to Alfred Lister}

'Chinese Boxing', The North China Herald, 13 July 1872, pp. 25-26

Lister, Alfred, 'A Chinese Farce', The China Revien, 1.1 (1872), 26-31

Lister, Alfred, 'Dr. Legge's Metrical Shi-King', The China Review, 5.1 (1876), 1-8

L. C. P., 'The Noble Art of Self-Defence in China', The China Review, 3.2 (1874), 84-92

Thomson, John and Rev. William R. Beach, Visit of His Royal Highness the Duke of Edinburgh, K.G., K.T., G.C.M.G., to Hongkong in 1869: Compiled from the Local Journals, and Other Sources (Hongkong: Noronha and Sons, Government Printers; London: Smith, Elder and Co., 1869)

\section{VII.1.2. Other Primary Sources}

Bingham, Elliot J., Narrative of the Expedition to China, from the Commencement of the Present Period, 2 vols (London: Henry Colburn, 1842), I

Bubishi: The Classic Manual of Combat, trans. by Patrick McCarthy (Tokyo: Tuttle, 2016)

Infantry Sword Exercises - Adjutant General's Office - Horse Guards (London: H. M.

Stationary Office, 1842)

'Pugilism', The Canton Register, 18 June 1829

Nisan, Davis S. and Liu Kangyi, The General Tian Wubeizhi: The Bubishi in Chinese Martial Arts History (Taipei: Lion Martial Arts Book Company, 2016)

'The Noble Art of Self Defence in China', The China Mail, 27 November 1884, p. 3

Wood, John George, Every Boy's Book: A Complete Encyclopedia of Sports and Amusements (London: Routledge, 1860)

Paris, Bibliothèque nationale de France, MS Chinois 5640

\section{VII.2. Secondary literature}

Antony, Robert J., Like Froth Floating on the Sea: The World of Pirates and Seafarers in Late Imperial South China (Berkeley: Institute of East Asian Studies University of California, 2003)

Bortez, Avron, Gods, Ghosts and Gangsters: Ritual Violence, Martial Arts, and Masculinity on the Margins of Chinese Society (Honolulu: University of Hawai'i Press, 2011)

Esherick, Joseph W., The Origins of the Boxer Uprising (Los Angeles: California University Press, 1987) 
Fletcher, Angharad, 'Hybridity in Hong Kong: the Tung Wah Hospital', Hektoen International: A Journal of the Medical Humanities, Spring (2015),

<https://hekint.org/2017/02/05/hybridity-in-hong-kong-the-tung-wah-hospital/> [accessed 11 April 2019]

Hamm, John Christopher, Paper Swordsmen: Jin Yong and the Modern Chinese Martial Arts Novel (Honolulu: University of Hawai'i Press, 2005)

Holcombe, Charles, 'Theater of Combat: A Critical Look at the Chinese Martial Arts', The Historian, 52.3 (1990), 411-31

Howell, Philip, 'Race, Space and the Regulation of Prostitution in Colonial Hong Kong', Urban History, 31.2 (2004), 229-48

Judkins, Benamin N., 'Inventing Kung Fu', JOMEC, 5 (2014), $<\underline{\text { https://jomec.cardiffuniversitypress.org/articles/abstract/10.18573/j.2014.10272/ }}$

$>$ [accessed 11 April 2018]

Judkins, Benjamin N., 'Jingwu and the Creation of the "Kung Fu" Brand', $<$ https://chinesemartialstudies.com/2018/06/24/iingwu-and-the-creation-of-thekung-fu-brand/> [accessed 11 April 2018]

Judkins, Benjamin and Jon Nielson, The Creation of Wing Chun: A Social History of the Southern Chinese Martial Arts (Albany: SUNY Press, 2015)

Kennedy, Brian and Elizabeth Guo, Chinese Martial Arts Training Manuals: A Historical Survey (Berkeley: Blue Snake Books, 2005)

Kennedy, Brian and Elizabeth Guo, Jingwu: The School that Transformed Kung Fu (Berkeley: Blue Snake Books, 2010)

Lorge, Peter A., Chinese Martial Arts: From Antiquity to the Twenty-First Century (Cambridge and New York: Cambridge University Press, 2012)

Lorge, Peter, 'Early Chinese Works on Martial Arts', in The Martial Arts Studies Reader, ed. by Paul Bowman (London and New York: Rowman \& Littlefield, 2018), pp. 1326

Molasky, Michael, 'The Phone Book Project: Tracing the Diffusion of Asian Martial Arts in America through the Yellow Pages', in The Martial Arts Studies Reader, ed. by Paul Bowman (London and New York: Rowman \& Littlefield, 2018), pp. 57-72

Morris, Andrew, Marrow of the Nation: A History of Sport and Physical Culture in Republican China (Berkeley: University of California Press, 2004)

Phillips, Scott Park, Possible Origins: A Cultural History of the Chinese Martial Arts, Theater and Religion (Boulder: Angry Baby Books, 2016)

Robinson, David, Bandits, Eunuchs and the Son of Heaven: Rebellion and the Economy of Violence in Mid-Ming China (Honolulu: University of Hawai'i Press, 2001)

Shahar, Meir, The Shaolin Monastery: History, Religion, and the Chinese Martial Arts (Honolulu: Hawai'i University Press, 2008)

Tsang, Steve, A Modern History of Hong Kong (New York: I. B. Tauris, 2007) 
Tsang, Steve, Governing Hong Kong: Administrative Officers from the 19th Century to the Handover to China, 1862-1977 (New York: I. B. Tauris, 2007)

Wakeman, Frederic Jr., Strangers at the Gate: Social Disorder in Southern China, 1839-1861 (Berkeley and Los Angeles: University of California Press, 1997)

Wells, Marnix, Scholar Boxer: Chang Naizhou's Theory of Internal Martial Arts and the Evolution of Taijiquan (Berkeley: North Atlantic Books, 2005) 